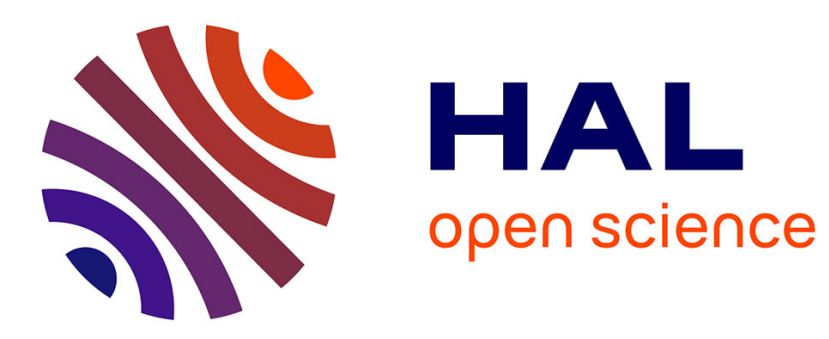

\title{
Indoor Location Tracking Based on a Discrete Event Model
}

\author{
Mickaël Danancher, Jean-Jacques Lesage, Lothar Litz
}

\section{To cite this version:}

Mickaël Danancher, Jean-Jacques Lesage, Lothar Litz. Indoor Location Tracking Based on a Discrete Event Model. International Conference on Smart Homes and Health Telematics, ICOST 2012, Jun 2012, Artimino, Italy. pp.262-265, 10.1007/978-3-642-30779-9_40 . hal-00709173

\section{HAL Id: hal-00709173 https://hal.science/hal-00709173}

Submitted on 18 Jun 2012

HAL is a multi-disciplinary open access archive for the deposit and dissemination of scientific research documents, whether they are published or not. The documents may come from teaching and research institutions in France or abroad, or from public or private research centers.
L'archive ouverte pluridisciplinaire HAL, est destinée au dépôt et à la diffusion de documents scientifiques de niveau recherche, publiés ou non, émanant des établissements d'enseignement et de recherche français ou étrangers, des laboratoires publics ou privés. 


\title{
Indoor Location Tracking based on a Discrete Event Model
}

\author{
Mickaël Danancher ${ }^{1,2}$, Jean-Jacques Lesage ${ }^{1}$, and Lothar Litz ${ }^{2}$ \\ 1 Automated Production Research Laboratory (LURPA), ENS Cachan, France \\ \{danancher, lesage\}@lurpa.ens-cachan.fr \\ ${ }^{2}$ Institute of Automatic Control, University of Kaiserslautern, Germany \\ litz@eit.uni-kl.de
}

\begin{abstract}
Some Ambient Assisted Living approaches are based on location tracking of the inhabitant. In this paper special finite automata are introduced to describe the dynamic indoor tracking process. A method to systematically generate the automaton is presented only using the topology and the sensor instrumentation of the house. Based on the discrete event model of the automaton an algorithm for location tracking has been developed. To clarify the foregoing an illustrative example is used throughout the paper.
\end{abstract}

Keywords: Ambient Assisted Living, Discrete Event System, Finite Automata, Location Tracking

\section{Introduction}

The increasing of life expectancy leads to new issues concerning the autonomy and the independence of elderly or disabled people. To cope with this important society problem, numerous Ambient Assisted Living (AAL) approaches are developed.

Some recent works are dedicated to the location tracking of one or more inhabitants. One of the basic techniques consists in determining if the inhabitant is at home or if the house is empty. Such an home occupancy approach, based for example on the monitoring of the power consumption and the ambient light, is presented in [1]. More accurate location tracking approaches aim to get the exact location of the inhabitant within his house. For instance, two approaches [2,3] are considering houses equipped with binary sensors (motion detectors, switches...). In [2], the knowledge of the real-time location of the inhabitant is aimed to improve the quality of the detection of health problems. In [3], the current location is tracked and the future location is predicted in order to optimize the energy consumption of the house. Despite a common location tracking objective, different models are used in the two approaches. Two graphs (one representing the connectivity of zones and another representing the connectivity of the sensors) are used in [3] whereas a Finite State Machine is taken as a model of the house in [2]. Nevertheless, in both cases the building of the model is only based on the knowledge of an expert. No methodology is proposed for a 
systematic construction of this model starting from the topology and from the instrumentation of the house. In both approaches, the possible inaccuracy of the location is envisaged but the causes of this uncertainty and its relation to the chosen instrumentation are not examined. Furthermore, neither the relationship between the model and the signals emitted by the sensors installed in the house nor the location tracking algorithm are clearly defined.

In this paper, a new approach for systematic generation of a Finite Automaton (FA) describing the motion of a single inhabitant in his home is proposed. This method is aimed to be the most generic and to be compliant with any home and any instrumentation with binary sensors only. This approach is described in the next section. The application of this approach on a case study is given in section 3. Finally, a conclusion and an outlook for future works are given.

\section{Overview of the proposed approach}

In the case the instrumentation of a house is performed using binary sensors only, the tenant moving in the house can be observed through signal events emitted by the sensors. The problem of location tracking of an inhabitant can then be considered as a Discrete Event System (DES) modeling problem. An appropriate way to model such a behavior is to use Finite Automata (FA). A FA is a quadruplet $\left\langle Q, \Sigma, T, Q_{0}\right\rangle$ with $Q$ a set of states, $\Sigma$ a set of input events, $T \subseteq Q \times \Sigma \times Q$ a transition relation between states, labeled with input events, $Q_{0} \subseteq Q$ a set of initial states.

An overview of the proposed approach for the systematic construction of a FA, representing the possible motion of an inhabitant into a house (or an apartment) equipped with binary sensors and its use for tracking the location of the inhabitant is given in Fig. 1.

In a first step, the topology of the apartment has to be described using a matrix-based formalism representing the topological links between the different rooms of the apartment. A Topology Graph is then systematically generated (1). For each room of the house, a node is created and for each direct path between two rooms, an edge between the two corresponding nodes is defined. For a given apartment, it is assumed that only one topology can be described, and thus only one Topology Graph can be generated.

In a second step, one or several possible instrumentations of the apartment with binary sensors have to be described. For each of these instrumentations, matrices representing the detectability area of each sensor are written. Knowing the Topology Graph previously built, a second algorithm allows the systematic generation of a Detectable Motion Automaton (DMA) (2). Each transition of the $D M A$ representing a path between two rooms is associated to the events of sensors that can be observed when the inhabitant is moving between the rooms.

In a third step, the relevance of each of the possible instrumentations (in terms of ability to detect the movements of the inhabitant and precision of its location) can be evaluated by analyzing the $D M A$. This evaluation leads to the validation of a given instrumentation or to the choice of the best one 
among several possible instrumentations (3). The algorithm consists in choosing the instrumentation minimizing the number of undetectable and inaccurately detectable changes of location of the inhabitant.

Finally, real time location of the inhabitant and its tracking during his movements into the apartment can be performed for the chosen $D M A$ (4). The current state $S$ of $D M A$ represents the location of the inhabitant and $S$ is updated according to the observed events.



Fig. 1. Global view of the proposed approach

\section{A case study}

This approach has been applied to a real house with people living inside. The topology and the current instrumentation of the chosen house are shown in Fig. 2 (a). It is composed of 5 rooms (a bedroom $A$, a bathroom $B$, a closet $C$, a living room $D$ and a vestibule $E$ ) and $O u t$. Different types of binary sensors such as Switches (e.g. $S W_{A 1}$ ), Windows Sensors (e.g. $W S_{B}$ ), Door Sensors (e.g. $D S_{E}$ ) and Motion Detectors (e.g. $M D_{D}$ ) are installed in the different rooms.

Based on the formalization of the topology and the instrumentation using vectors and matrices, the $D M A$ is generated. It is shown in Fig. 2 (b).

To define the initial state of $D M A$, a simple method is to install the user interface in a particular room (in our case in the living room $D$ ). Each time the monitor is initialized by the inhabitant, it is known that he is in this specific room and then the location tracking algorithm is correctly initialized.

Experimental results have shown that location tracking using this model performs well under two conditions. There has to be only one inhabitant in the 


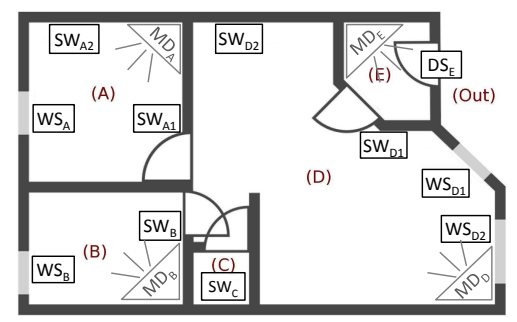

(a) Topology and instrumentation

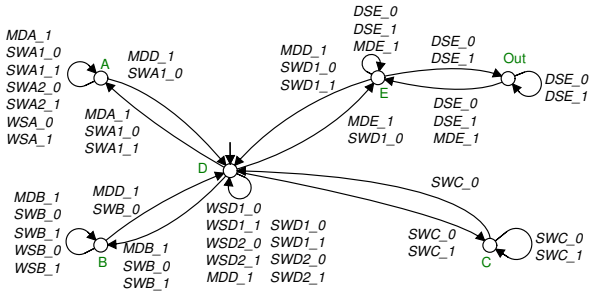

(b) Detectable Motion Automaton

Fig. 2. Application on a case study

house and no other one nor a pet. It is also assumed that no fault of any sensor occur. Future work will be devoted to relax these two hypotheses.

\section{Conclusion and future work}

In this paper, a method aiming to systematically build a model of any instrumented home has been introduced. It was tested in a real environment and showed promising results.

The use of FA is proposed because this is a standard formalism in the field of DES. Many developments have been introduced to deal with more sophisticated behaviors. For instance, a timed behavior can be modeled using timed automata or the uncertainty can be taken into account using stochastic automata.

Future work on this topic will be devoted to the location tracking coping with multiple inhabitants. Some promising results have been presented in [4] but the DES theory could be of particular interest to deal with this issue. Another challenge is to use the proposed FA with an algorithm of sensor fault detection and isolation. These methods are devoted to manufacturing systems but it seems that they can be adapted to AAL issues.

\section{References}

1. S. Makonin and F. Popowich, "An Intelligent Agent for Determining Home Occupancy Using Power Monitors and Light Sensors," in Proc. of the 9th Int. Conf. on Smart Homes and Health Telematics, ICOST'11, Montreal, Canada, pp. 236-240, 2011.

2. M. Floeck, L. Litz, and T. Rodner, "An Ambient Approach to Emergency Detection based on Location Tracking," in Proc. of the 9th Int. Conf. on Smart Homes and Health Telematics, ICOST'11, Montreal, Canada, pp. 296-302, 2011.

3. A. Roy, S. K. Das Bhaumik, A. Bhattacharya, K. Basu, D. J. Cook, and S. K. Das, "Location Aware Resource Management in Smart Homes," in Proc. of the IEEE Int. Conf. on Pervasive Computing and Communications PerCom, pp. 481-488, 2003.

4. A. S. Crandall and D. J. Cook, "Coping with multiple residents in a smart environment," Journal of Ambient Intelligence and Smart Environments, vol. 1, no. 4, pp. 323-334, 2009. 